ARTICLE

\title{
Monte-Carlo Based Numerical Modeling and Simulation of Criticality Conditions Occurrence in Natural Reactor Zone 9 in Oklo Deposit (Gabon)
}

\author{
Salah-Eddine BENTRIDI ${ }^{1, *}$, Benoît GALL ${ }^{2}$, \\ François GAUTHIER-LAFAYE ${ }^{1}$ and Abdeslam SEGHOUR ${ }^{3}$ \\ ${ }^{1}$ Laboratoire d'Hydrologie et de Géochimie de Strasbourg, 1 rue Blessig, 67084 Strasbourg, France \\ ${ }^{2}$ Institut Pluridisciplinaire Hubert Curien, UMR 7871, 23 rue du Loess 67037 Strasbourg, France \\ ${ }^{3}$ Centre de Recherches Nucléaires d'Alger CRNA, 2 Bvd Frantz Fanon 16002 Alger, Algeria
}

\begin{abstract}
The occurrence of the criticality with analogue modelled configurations of the fossil reactor zone $n^{\circ} 9$ (RZ9) from Oklo uranium deposit in Gabon is studied. The RZ9 and the other reaction zones 7 and 8, of the same deposit sector are characterized by a low thickness compared to other zones 1 to 6 and an important presence of organic matter with a lower $U$ content. This makes the simulations performed in the past unable to explain the occurrence of that phenomenon in such zones. In the present work an extrapolation to 2 billion years ago as an initial state of the reactor is done using the MCNP Monte-Carlo based code. To make it more close to the geological reality experimental conditions and geometry, possible porosity, moderators and minimal Uranium content are considered. The minimal critical configuration is obtained by variation of a set of geometrical and physical parameters around the estimated composition of the reactor area. A set of simulations computing the corresponding effective multiplication factor $k_{\mathrm{eff}}$, and reactivity are presented. The effect of organic matter as well as the influence on the criticality is discussed.
\end{abstract}

KEYWORDS: Oklo, natural nuclear reactor, criticality, Monte Carlo, neutron transport, simulation, modeling, organic matter, uranium

\section{Introduction}

The reactor zone $n^{\circ} 9$ (RZ9) from Oklo uranium deposit in Gabon is one of about fifteen natural nuclear reactors discovered since 1972 and known as the "Oklo phenomenon" that took place 1,950 million years ago. ${ }^{1)}$ This is unique and interesting in the way it was formed, launched and sustained $^{3)}$ on some hundred thousand years without any human contribution. ${ }^{6,13)}$ The special interest for this reactor came from the difficulty encountered to explain the occurrence of the criticality in such site. The earlier simulations developed for the Oklo reactors ${ }^{8)}$ could not explain the criticality in such small reactor. Furthermore, presence of organic matter $(\mathrm{OM})$ registered around the big reactors of Oklo like RZ2, is observed even inside the RZ9 core itself, ${ }^{8,9,12,18)}$ with such lower $\mathrm{U}$ content compared to the other zones. Today, the possibility offered by the Monte-Carlo code MCNP, ${ }^{14,16)}$ allows us to make more realistic and detailed numerical computations to study criticality in such a system. For this purpose the minimal size needed for criticality was studied with respect to a realistic porosity, OM, water, $\mathrm{U}$ and poisons content. Several geometries have been defined in order to consider also the effect of surrounding rocks. Criticality in RZ9 can be explained by the present work.

\section{Geological Context of the Reactors}

The Oklo Uranium deposit is located in a 2.1 billion years old sedimentary series which belongs to the Franceville ba-

*Corresponding author, E-mail: bentridi@unistra.fr

(c) 2011 Atomic Energy Society of Japan, All Rights Reserved.

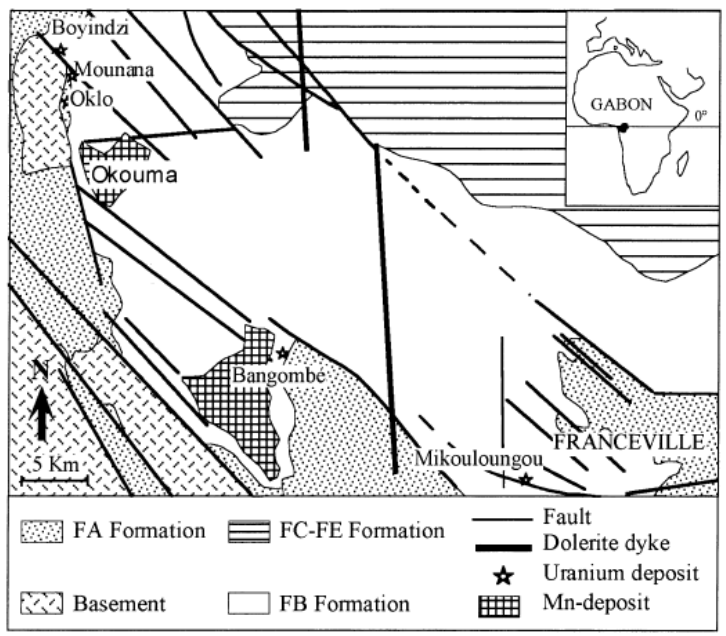

Fig. 1 Geological map of the Franceville basin in Gabon ${ }^{1)}$

sin in the southeast part of the Gabon Republic (Fig. 1). The basin is identified as a succession of five main formations, labelled from A to E (bottom to top). The zone of interest is the mineralized layer located at the top of the A formation. ${ }^{7,8)}$ The reaction zones were found in a clay envelope, formed during and after the operating and cooling phases of reactors. The ore is mainly made of quartz, clays (chlorite and illite) and organic matter as solid bitumen. ${ }^{8,10,23)}$ Heavy minerals ${ }^{11)}$ (zircon, thorite, monazite) represent a minor phase mainly located in conglomerate layers. The uranium content averaged on the whole deposit is estimated to $0.4 \%$ 


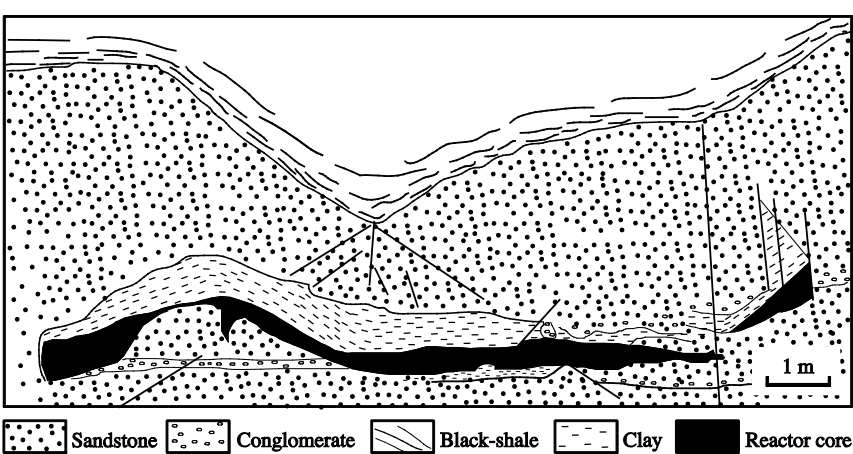

Fig. 2 Horizontal outcrop of the reactor $n^{\circ} 9$ in the Oklo depo$\mathrm{sit}^{22)}$

wgt with some rich amasses ranging from 2 to 15\%. Uranium as pitchblende inclusions is closely associated with organic matter, which played a reducing role for uranium precipitation. ${ }^{8,22)}$ The burned up uranium in the reactors is mainly made of cubic uraninite, which is often closely connected to OM. The Oklo deposit is the oldest high grade uranium deposit located in a sedimentary sequence and it can be considered as an ancient hydrocarbons field prior to be an uranium deposit ${ }^{10)}$. Realistic rock porosity in such sandstone rock reservoir may therefore range from $20 \%$ to $40 \%{ }^{17)}$ This can clearly be observed in the zones 7 to 9 which show important quantities of the degraded O.M. ${ }^{8,12,22)}$ The operating time of the reactor $n^{\circ} 9$ is estimated to 220,000 years. ${ }^{12,18)}$ At that time, the reactor zone was buried under 2,000 $\mathrm{m}$ of rocks resulting in temperature and pressure conditions around $150{ }^{\circ} \mathrm{C}$ and 200 bars respectively, assuming hydrostatic conditions. Those conditions are even less restrictive than the PWR Reactors ones $\left(220^{\circ} \mathrm{C}\right.$ and 155 bars) chosen to maintain water liquid., ${ }^{8,22}$

\section{Presentation of the Reaction Zone $\mathbf{n}^{\circ} \mathbf{9}$ :}

Discovered by Gauthier-Lafaye (at the end of 1978), the RZ9 is localized 300 meters far from the northern sector (RZ1 to 6). At present time, the RZ9 is a few centimetres thick lens shaped with a $45^{\circ}$ dip. It is spreading out on $7 \mathrm{~m}$ long and $12 \mathrm{~m}$ width, with two wings fragments in the southern part (Fig. 2). An important abundance of degraded organic matter in form of bitumen was observed in the RZ9 with the weight ratio U/C usually superior to 0.5 . The present time U content obtained from analysed samples, range between 25 and 30\% wgt (considered on dehydrated ore). ${ }^{8)}$ In previous studies, this geometry was considered to be too thin to allow criticality due to important geometrical induced leakage of fission neutrons and the low $U$ content was considered to be insufficient to assure a criticality in such case. $^{2,8)}$

\section{Modeling of the Reactor}

Previous works have shown that the main effect of the fission reactions on the hosted rocks results from an intense hydrothermal alteration due to the heating of the fluids., ${ }^{80}$ The main consequences of such an alteration are the dissolution of the quartz, the crystallisation of new clay minerals

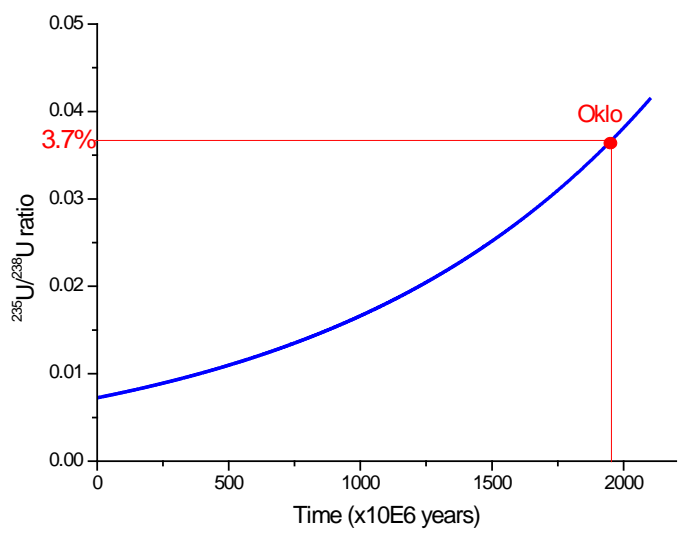

Fig. 3 Evolution of the ${ }^{235} U /{ }^{238} U$ ratio versus time indicating the Oklo reactors launching ${ }^{4)}$

(mainly illite of high temperature and $\mathrm{Al}$ and $\mathrm{Mg}$ rich chlorites) and an overall increase of the uranium content which can reach values up to $60 \% .^{5,10)}$ Therefore, in its initial configuration the RZ9 was richer in quartz and poorer in $U$ than the present time reactor ore. We consider also, that prior the fission reaction operations, the RZ9 was essentially a hydrocarbons (HC) trap in which the uranium concentrated continuously until the conditions of criticality were reached. This process induces a correlation between the porosity, HC and the U contents. This implies an enhancing of thermalisation processes efficiency where $U$ is located. This plays an important role for reactor neutronics.

The porosity in the mineralised hydrocarbon-rich sandstones (MHS) can be set to the values observed in rocks reservoirs of hydrocarbons deposits, which ranges from 20 to $40 \%$ of the ore volume. ${ }^{8,17)}$ As a result of the radioactive decay constant difference for the two uranium isotopes 235 and 238, the ${ }^{235} \mathrm{U} /{ }^{238} \mathrm{U}$ ratio 1.95 billion years ago is calculated to be $3.7 \%$ wgt. $^{4,5)}$ This value is very close to the PWR reactors fuel enrichment ${ }^{8)}$ (Fig. 3 ).

\section{Physical Modeling}

The typical ore sample used in this study is numerically defined by two main volumes (i) a solid volume (clay, $\mathrm{UO}_{2}$, silica) and (ii) a fluid volume fraction located in all forms of porosity even the intrinsic porosity of clay (moderator: water and/or H.C) designed by $\phi_{\mathrm{T}}$ and given by the following relationship:

$$
\phi_{T}=\frac{V_{\text {free }}}{V_{\text {Total }}}=\frac{V_{\text {free }}}{V_{\text {Solid }}+V_{\text {free }}},
$$

where $V_{\text {free }}$ Design the free volume could occupied by any fluid.

The solid part deduced from the difference between the volume unit and fraction of fluid (apparent porosity) is divided in two sub volumes: sandstone + clay and Uraninite. The parameter used to define the ore enrichment is designed by $\mathrm{V}_{\mathrm{UO2}}$. It represents the volume of the uraninite in a volume of $1 \mathrm{~cm}^{3}$ of the hydrated ore. We can then, deduce $V_{U}$ the uranium content defined as the ratio of the existing uranium mass in the volume unit to the total mass of the dehydrated rich ore. 
Table 1 Target thickness and isotopic enrichment

\begin{tabular}{ccc|cc}
\hline \multicolumn{2}{c|}{ Chlorite } & \multicolumn{2}{c}{ Illite } \\
\hline & Atom/mesh & weight & Atom/mesh & weight \\
\hline Si & 3.17 & $\mathbf{8 9 . 1}$ & 2.87 & $\mathbf{8 0 . 6 5}$ \\
$\mathbf{A l}$ & 2.49 & $\mathbf{6 7 . 2}$ & 3.22 & $\mathbf{8 6 . 9 4}$ \\
$\mathbf{M g}$ & 0.18 & $\mathbf{4 . 4}$ & 1.04 & $\mathbf{2 5 . 2 7}$ \\
$\mathbf{F e}$ & 0.14 & $\mathbf{7 . 8}$ & 2.88 & $\mathbf{1 6 0 . 7}$ \\
$\mathbf{N a}$ & 0.03 & $\mathbf{0 . 7}$ & 0.02 & $\mathbf{0 . 4 6}$ \\
$\mathbf{K}$ & 0.72 & $\mathbf{2 8 . 2}$ & 0.03 & $\mathbf{1 . 1 7 3}$ \\
OH & 2 & $\mathbf{3 4}$ & 6 & $\mathbf{1 0 2}$ \\
H3O & 0.35 & $\mathbf{6 . 7}$ & 0 & $\mathbf{0}$ \\
O & 10 & $\mathbf{1 6 0}$ & 10 & $\mathbf{1 6 0}$ \\
total & - & $\mathbf{3 9 8 . 1}$ & & $\mathbf{6 1 7 . 2}$ \\
\hline
\end{tabular}

In our approach we define a MHS sample with $90 \%$ silica and $10 \%$ clay.

The mass transfer of silica during the reactor operating leads to significant volume reduction. This hydrothermal process leaded to present time reactor geometry and chemical composition. It means that the present measured thickness is about 10 times thinner than the initial one. ${ }^{8,20)}$

This $U$ concentration process is very important for neutronics because it occurs in parallel to nuclear consumption of ${ }^{235} \mathrm{U}$ and can explain the quite high value of final burn-up of the fuel.

In the MCNP code, each volume is filled with a defined material. In the present case of inhomogeneous volumes, we replaced the realistic description of pure millimetric sub-clay elements by a mean composition. This simplification could be done due to the fact that the mean free path of neutrons in such materials is significantly larger than the rock grain element scale. In the simulation code, each material composition was given in atoms per unit of volume. ${ }^{14,16)}$ The major element composition of the clay is given by the values in Table 1. ${ }^{22)}$

Assuming incompressible materials, the different densities are computed as follows:

$$
\begin{aligned}
& \frac{1}{\rho_{\text {clay }}}=\frac{\%_{\text {chlorite }}^{\text {mass }}}{\rho_{\text {chlorite }}}+\frac{\%_{\text {illite }}^{\text {mass }}}{\rho_{\text {illite }}}, \\
& \frac{1}{\rho_{\text {MHS }}}=\frac{\%_{\text {clay }}^{\text {mass }}}{\rho_{\text {clay }}}+\frac{\%_{\text {Qrtz }}^{\text {mass }}}{\rho_{\text {Qrtz }}}, \\
& \rho_{\text {solid }}=\%_{\text {UO2 }}^{\text {vol }} \times \rho_{\text {UO2 }}+\%_{\text {MHS }}^{\text {vol }} \times \rho_{\text {MHS }}=f_{U O 2}+f_{M H S},
\end{aligned}
$$

Where we define the substance mass fraction for an ingredient $\mathrm{X}$ :

$$
f_{X}=\%_{X}^{\mathrm{Vol}} \times \rho_{X} .
$$

Then, we find the total hydrated ore density:

$$
\rho_{\text {ore }}=f_{U O 2}+f_{M H S}+f_{\text {fluid }}
$$

For each value of $\mathrm{V}_{\mathrm{UO} 2}$ and $\phi_{\mathrm{T}}$ we obtain the corresponding initial ore density and the contribution in percent of each chemical element of the compound. The whole ore is considered to be homogenous.

In this study, we assume that the initial core is poisons-free.

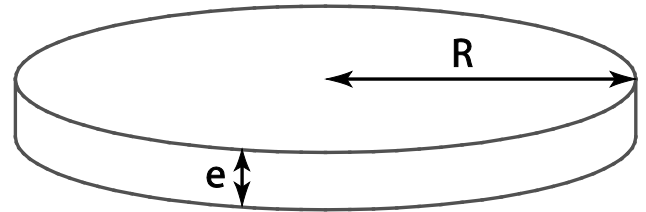

Fig. 4 Geometrical model of the reflector-less reactor

\section{Geometrical Modeling}

According to geological statements, we consider in the model a cylindrical geometry for the RZ9. This assumption reduces the geometrical parameters to the radius and the thickness of a cylinder, hereafter referred as " $R$ " and " $e$ " respectively (Fig. 4).

Furthermore, surrounding reflectors are also taken in account allowing to study their effect on the reactivity and therefore on the reduction of the geometrical dimensions of the initial reactor.

\section{Reflector-Less Fresh Core}

The Monte-Carlo based Code used in this study is the MCNP 5.1 release (Monte-Carlo N-Particles); ${ }^{15,16)}$ this code is frequently used in radiations-matter interactions simulations in general way and especially in reactor calculations. Giving a good analogy between the probabilistic numerical methods and the random characters of particles at nuclear scale, this code allowed us to carry out many simulations in reasonable time (between 80 and 120 min for each parameter value to get the source convergence) and obtain reliable results. The starting source was defined as a diffuse source of neutrons issued by spontaneous fission of uranium. Using the cross-section library included in MCNP, and the Kcode option we could compute the effective multiplication factor $\mathrm{k}_{\text {eff. }}$

\section{Standard Reflector-Less Fresh Core}

In this contribution, we call fresh core the initial critical volume. Its volume is not well known since its extension varied along the reactor operation. Since uranium concentration process led to fluctuation in ore $U$ content, the aim of the first part of this work was to determine the minimal size of an inhomogeneity compatible with criticality for a poisons-free core.

Different configurations of the fresh poisons-free core were simulated by varying the physical parameters $\mathrm{R}$ and $\mathrm{e}$ under different realistic physical conditions $\left(\mathrm{V}_{\mathrm{UO} 2}\right.$ and $\left.\phi_{\mathrm{T}}\right)$.

These conditions were chosen for $\phi_{\mathrm{T}}=20,30$ and $40 \%$ by varying $\mathrm{V}_{\mathrm{UO} 2}$ from 4 to $7 \%$, taking into account the weight fraction induced changes. In this first phase porosity was filled with light water (density $\rho_{\mathrm{wtr}}=0.9232 \mathrm{~g} / \mathrm{cc}$ ) ${ }^{8,19)}$ used as moderator, under the pressure and temperature conditions: 200 bars and $150{ }^{\circ} \mathrm{C}$.

The initial reactor thickness (e) was varied from $60 \mathrm{~cm}$ to $100 \mathrm{~cm}$ by $10 \mathrm{~cm}$ steps while its radius (R) had a $20 \mathrm{~cm}$ variations steps. Figure 5 displays the results for $\mathrm{V}_{\mathrm{UO} 2}=4 \%$ and $\phi_{\mathrm{T}}=20 \%$. It shows that criticality can be found with a $160 \mathrm{~cm}$ radius for a one meter thickness initial reflector-less reactor. If promising criticality is found, needed reactor size is still quite big in this low concentration and low porosity 


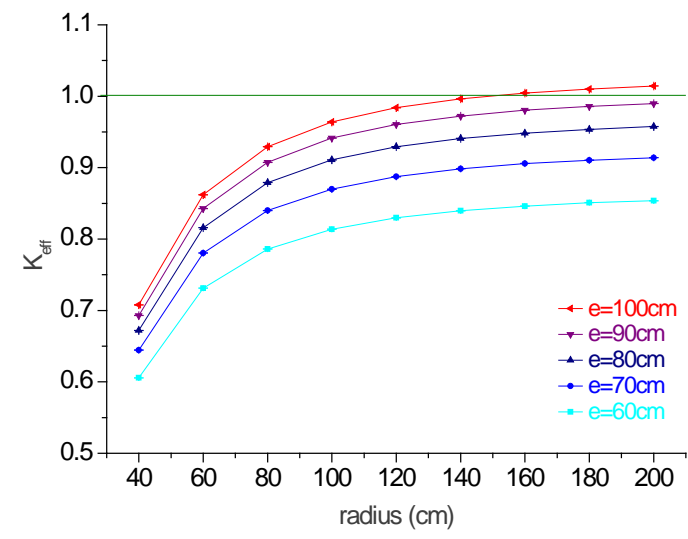

Fig. 5 Multiplication factor evolution versus radius of reflector-less fresh core reactor for $\phi_{\mathrm{T}}=20 \%$ and $\mathrm{V}_{\mathrm{UO} 2}=4 \%$

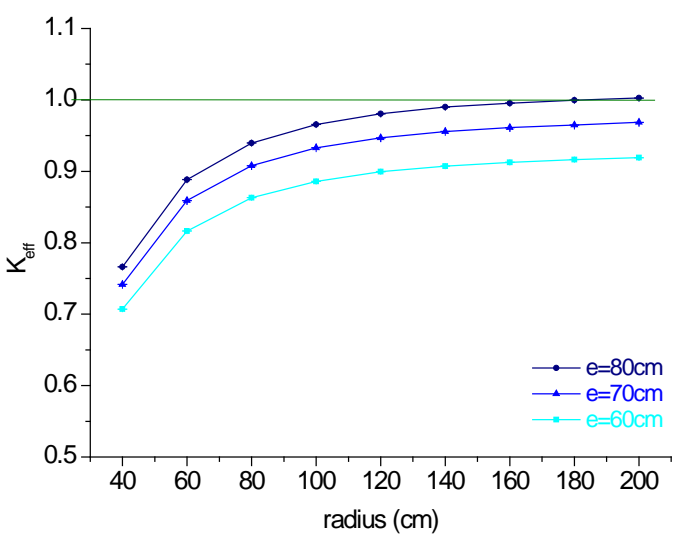

Fig. 6 Multiplication factor evolution versus radius of reflector-less fresh core reactor for $\phi_{\mathrm{T}}=30 \%$ and $\mathrm{V}_{\mathrm{UO} 2}=4 \%$

case.

Figures 6 and 7 display the effective multiplication factor $\mathrm{k}_{\mathrm{eff}}$ at $\mathrm{V}_{\mathrm{UO} 2}=4 \%$ for higher realistic porosities $\phi_{\mathrm{T}}=30$ and $40 \%$.

Following the increase of porosity the subsequent thermalisation efficiency increase led to smaller critical core as expected. Indeed the dimensions needed to the critical cylinders decreased from $\left(\mathrm{R}=160 \mathrm{~cm}, \mathrm{e}=100 \mathrm{~cm}\right.$ at $\left.\phi_{\mathrm{T}}=20 \%\right)$ to $\left(\mathrm{R}=140 \mathrm{~cm}, \mathrm{e}=90 \mathrm{~cm}\right.$ at $\left.\phi_{\mathrm{T}}=30 \%\right)$ and finally $(\mathrm{R}=125 \mathrm{~cm}$, $\mathrm{e}=80 \mathrm{~cm}$ at $\left.\phi_{\mathrm{T}}=40 \%\right)$.

In second stage, we varied the $\mathrm{V}_{\mathrm{UO} 2}$ parameter $\left(\mathrm{V}_{\mathrm{UO} 2}=4\right.$, 5, 6 and 7\%) with fixed porosity $\phi_{\mathrm{T}}=30 \%$ in $\mathrm{e}=70 \mathrm{~cm}$ reflector-less core. Figure 8 displays the multiplication factor $\mathrm{k}_{\mathrm{eff}}$ evolution with reactor radius. The obtained critical radii $\mathrm{R}=130 \mathrm{~cm}$ (5\%), $90 \mathrm{~cm}$ (6\%), $75 \mathrm{~cm}$ (7\%) proves that even in a reflector-less core, realistic critical volume can be obtained.

Since exact size of the fresh core is not well established, we also studied reactivity variation as a function of uranium density for several radii. Indeed the reactivity $\rho=(k-1) / k$ (expressed in pcm, $1 \mathrm{pcm}=0.001 \%$ ) measures with high sensitivity the core distance to criticality.

The results of these calculations are displayed in Fig. 9. We observe a quasi-linear increase of reactivity with $U$ density (averaged slope of $34,000 \mathrm{pcm} . \mathrm{cc} / \mathrm{g}$ ). For a $\mathrm{R}=80 \mathrm{~cm}$ and $\mathrm{e}=70 \mathrm{~cm}$ reflector-less reactor the needed $\mathrm{V}_{\mathrm{UO}}$ is $6.5 \%$

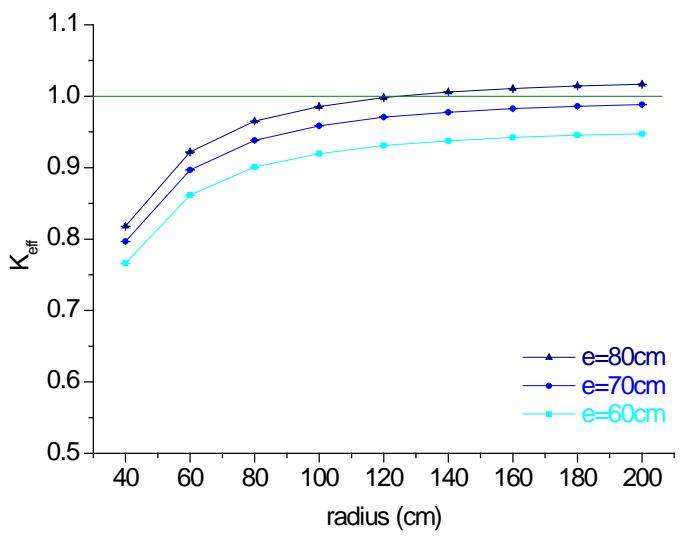

Fig. 7 Multiplication factor evolution versus radius of reflector-less fresh core reactor for $\phi_{\mathrm{T}}=40 \%$ and $\mathrm{V}_{\mathrm{UO} 2}=4 \%$

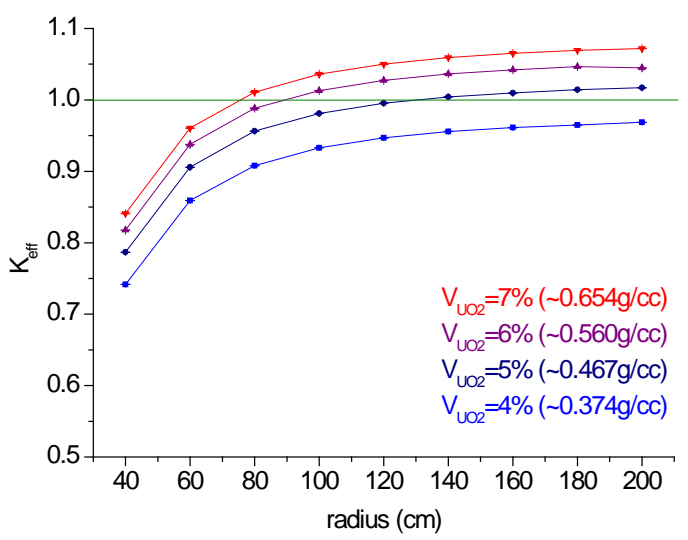

Fig. 8 Multiplication factor evolution versus reflector-less reactor radius for different $\mathrm{V}_{\mathrm{UO} 2}{ }^{\mathrm{a}}$

corresponding to $25.5 \% \mathrm{U}$ in a MHS (0.607 g/cc of U). This value was often found at Oklo. ${ }^{7,8)}$

This first parametrical study allowed us to build a first set of possible critical configurations, even if the criticality calculation did not involve reflectors. The size and physical conditions ( $\phi_{\mathrm{T}}$ and $\mathrm{V}_{\mathrm{UO} 2}$ ) of the initial critical reactor is shown to be realistic.

\section{Influence of Moderator Composition}

In the present section, using the same reflector-less geometry than before, we study the effect of the composition on the thermalisation of neutrons, and the criticality by filling all the porosity by:

- Water under normal (P,T) conditions (0.999 g/cc)

- Water under Oklo (P,T) conditions (0.923 g/cc)

- Alkane HC under normal (P,T) conditions (0.655 g/cc)

- Aromatic HC under normal (P,T) conditions (0.88 g/cc)

For the two types of HC we use a typical isomer molecule (resp. Hexane and benzene). The $\mathrm{H}-\mathrm{C}-\mathrm{O}$ composition of the $\mathrm{HC}$ compound used and thermal treatment used $(\mathrm{S}(\alpha, \beta))$ are given in Table 2.

It is to be noticed that it is very important to consider the right hydrogen binding with its mother molecule given by the thermal treatment used $(\mathrm{S}(\alpha, \beta)$ “mt” card in the MCNP code). This may affect strongly the results of the multiplication factor calculations. ${ }^{15)}$ 


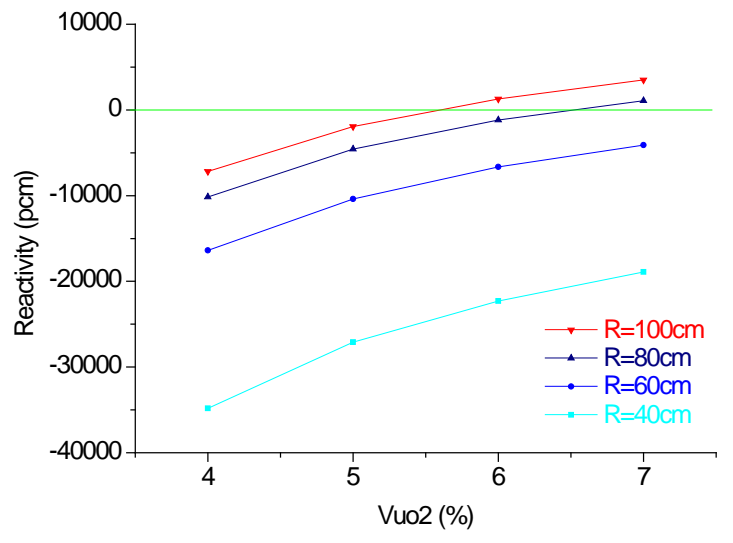

Fig. 9 Criticality variation versus uraninite volume

Table 2 Used moderators definition

\begin{tabular}{lccccc}
\hline Moderator & $\begin{array}{c}\text { Density } \\
\text { (g/cc) }\end{array}$ & $\begin{array}{c}\text { H } \\
\text { \%wgt }\end{array}$ & $\begin{array}{c}\mathbf{C} \\
\text { \%wgt }\end{array}$ & $\begin{array}{c}\text { O } \\
\text { \%wgt }\end{array}$ & $\begin{array}{c}\text { Available } \\
\text { S( } \boldsymbol{\alpha}, \boldsymbol{\beta})\end{array}$ \\
\hline Water & 0.9999 & 11.11 & 0 & 88.89 & Lwtr.60t \\
Water & 0.9232 & 11.11 & 0 & 88.89 & Lwtr.61t \\
Hexane & 0.6550 & 16.67 & 83.33 & 0 & Poly.60t \\
Benzene & 0.8800 & 07.7 & 92.3 & 0 & Benz.60t \\
\hline
\end{tabular}

The simulations are done for a $\mathrm{e}=70 \mathrm{~cm}$ reflector-less core under $\phi_{\mathrm{T}}=30 \%$ and $\mathrm{V}_{\mathrm{UO} 2}=4 \%$ physical conditions. Figure $\mathbf{1 0}$ displays the multiplication factors obtained with the four considered moderators. Results of simulations from previous section (light water under Oklo P,T conditions) is the middle curve. With respect to this, the aromatic one seems to be much less favourable and shows no criticality within the calculation range. On the other side, alkane curve shows a slightly better behaviour than water in Oklo $(\mathrm{P}, \mathrm{T})$ conditions. This curve almost fit the curve obtained with water also in normal $(\mathrm{P}, \mathrm{T})$ conditions. Since MCNP does not contain a library corresponding to alkane under Oklo $(\mathrm{P}, \mathrm{T})$ conditions the overlap of these two curves enables us to estimate that alkane behaves like water under Oklo conditions.

One can therefore conclude that water and alkane behave in a similar way and that aromatic compounds are much less efficient.

In initial conditions, porosity is filled by a mixture of hydrocarbons (Alkane + Aromatics) and water.

Under the severe thermal conditions induced by reactor operation, hydrothermal alteration can alter this mixture. In particular, the pyrolysis process increases the Aromatic/Alkane ratio. The reactor may then loose criticality unless the water/HC ratio and/or U concentration effects compensate it.

\section{Fresh Cores with Reflectors}

We consider in this section the fresh reactors and the effect of the surrounding rocks that play the double role of reflector and thermal neutrons contributor. The top and bottom reflectors are modelled with two $70 \mathrm{~cm}$ thick cylindrical layers and the core is surrounded by peripherical ring reflectors of the core thickness e (Fig. 11).

To be consistent with geological conditions lateral reflec-

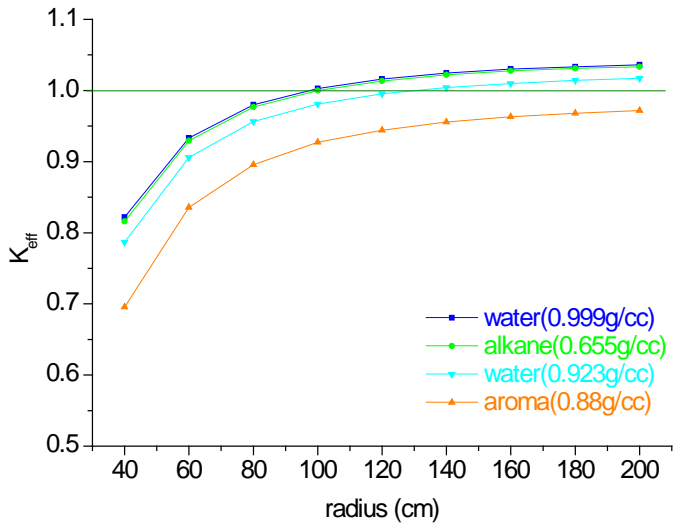

Fig. 10 Compared criticality according different moderators

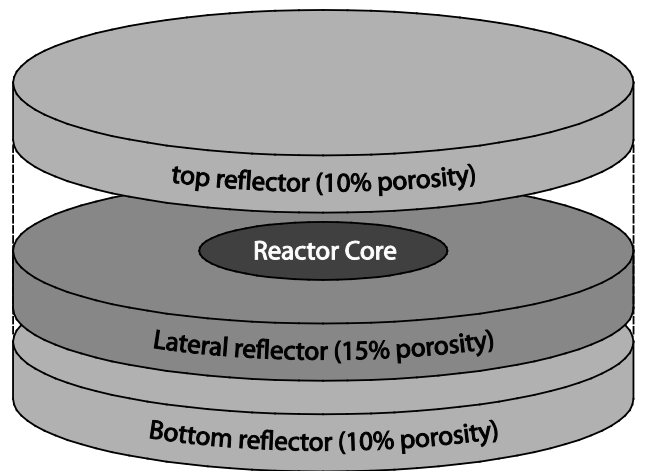

Fig. 11 Representation of reactor model with reflectors

tor has $15 \%$ porosity where the top/bottom has only $10 \%$. All reflectors are completely poor in uranium which represents the extreme unfavourable case since the lateral one is more often mineralised and is the extension matrix for the reactor. ${ }^{8,22)}$

The simulations are carried out for a $70 \mathrm{~cm}$ thick fresh core with $\mathrm{V}_{\mathrm{UO} 2}=5 \%$. For each value of $\phi_{\mathrm{T}}$ ranging from 20 to $40 \%$ the critical radius $R_{C}$ is determined with and without reflectors. These calculations led to the isocriticality lines for the two cases. They are given in Fig. 12.

First we see that the curve saturates for low $R_{C}$ and that $a$ minimal possible $\mathrm{R}_{\mathrm{C}}$ corresponds to each isocriticality line. These two curves also highlight the influence of the reflectors: adding reflector material end-up to a significant reduction of $\mathrm{R}_{\mathrm{C}}$ (approximately 30\% in the present case).

In the volume approach used in this study, it has to be notice that for the used $\mathrm{V}_{\mathrm{UO}}$ value, the conventional $\mathrm{U}$ content defined like the ratio between the $U$ mass and the dry ore mass, is ranging between 18.5 and $23.5 \%$ wgt.

\section{Conclusion and Perspectives}

Based on Monte-Carlo MCNP 5.1 code, the occurrence of criticality is studied within the framework of the natural nuclear reactor $n^{\circ} 9$ in Oklo deposit. In the first approach of a reflector-less fresh core, the ignition conditions under given realistic porosities and $U$ concentrations are established, using the proposed chemical composition of the initial ore. 


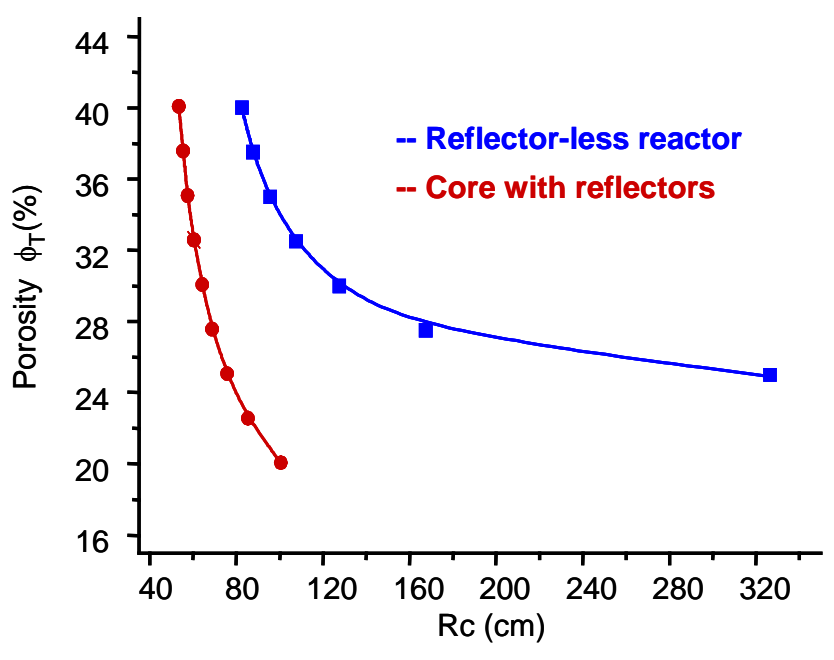

Fig. 12 Fresh core isocriticality line with and without reflectors for $\mathrm{V}_{\mathrm{UO} 2}=5 \%$

Despite the fact that the radial dimension stay too big for the lower porosities, those results become more interesting when the reflectors effect of materials in the close vicinity of the reactor is considered. With the same physical and chemical conditions it could be established that the radius of the initial critical fresh core don't exceed one meter. The reactivity study gives the sensitivity of the reactor with respect to U density, promising smaller possible configurations for more U presence.

The important presence of altered hydrocarbons inside the reactor core itself at the final state motivates the study of the influence of hydrocarbons like moderator. Using simple molecules from two main hydrocarbons families with available data about organic matters, similarity efficiency under the same conditions is shown between light water and alkane type.

This first study constitutes a perfect framework in order to describe influence of the poisons and give an approach of the reactor dynamics through snapshots of relevant intermediate situations. This work opens nice perspectives for the understanding of the Oklo phenomenon.

\section{Acknowledgment}

The authors express their thanks to A. Clement (Computer Dept. chief in LHyGeS) for all computer existent facilities provided to the achievement of those calculations.

\section{References}

1) F. Gauthier-Lafaye, "The constraint for the occurrence of uranium deposits and natural nuclear fission reactors in the paleoproterozoic Franceville Basin (Gabon)," Geol. Soc. Am. Mem., 198, 157-167 (2006).

2) Y. V. Petrov et al., "Natural nuclear reactor at Oklo and variation of fundamental constants: Computation of neutronics of a fresh core," Phys. Rev., C74, 064610, 1-17 (2006).

3) A. P. Meshik, C. M. Hohenberg, O. V. Pravdivtseva, "Record of Cycling Operating of the Natural Nuclear Reactor in the Oklo/Okelobondo Area in Gabon,” Phys. Rev. Lett., 93[18], 1-4 (2004).
4) F. Gauthier-Lafaye, F. Weber, "Natural nuclear fission reactors: time constraints for occurrence, and their relation to uranium and manganese deposits and to the evolution of the atmosphere," Precamb. Res., 120, 81-100 (2003).

5) F. Gauthier-Lafaye, "From nuclear fuels to waste: current research: 2 billion year old natural analogs for nuclear waste disposal: the natural nuclear fission reactors in Gabon (Africa)," C. R. Physique, 3, 839-849 (2002).

6) F. Gauthier-Lafaye, "The last natural nuclear fission reactor," Nature, 387, 337 (1997).

7) F. Gauthier-Lafaye, P. Holliger, P. L. Blanc, "Natural fission reactors in the Franceville basin, Gabon: A review of the conditions and results of "critical event" in a geological system," Geo. Cosmo. Acta., 60[23], 4831-4852 (1996).

8) R. Naudet, Oklo: Des réacteurs nucléaires fossiles - Etude physique, Série Synthèses: C.E.A, éditions Eyrolles, 685 (1991).

9) F. Cortial, F. Gauthier-Lafaye, A. Oberlin, G. Lacrampe-Couloume, F. Weber, "Charaterization of organic matter associated with uranium deposits in the Francevillian Formation of Gabon (Lower Proterzoic),” Org. Chem., 15[1], 73-85 (1990).

10) F. Gauthier-Lafaye, F. Weber, "The Francevillian (Lower Proterozoic) Uranium Ore Deposits of Gabon,” Eco. Geo. 84, 2267-2285 (1989).

11) H. Hidaka et al. "Abundance of fissiogenic and pre-reactor natural rare-earth elements in a uranium ore sample from Oklo,” Geoch. J., 22, 47-54 (1988).

12) R. D. Loss et al. "The Oklo natural reactors: cumulative fission yields and nuclear characteristics of Reactor Zone 9," Earth Plan. Sci. Lett., 89, 193-206 (1988).

13) P. K. Kuroda, "On the Nuclear Physical Stability of the Uranium Minerals,” J. Chem. Phys., 25, 781 (1956).

14) J. K. Shultis, R. E. Faw, An MCNP Primer, Kansas State University (2006).

15) C. D. Harmon et al., Criticality Calculations with MCNP5: A Primer $2^{\text {nd }}$ Edition, LA-UR-04-0294, Los Alamos National Laboratory (LANL) (2004).

16) X-5 Monte Carlo Team, MCNP - A General N-Particle Transport Code, Version 5, LA-UR-03-1987, Los Alamos National Laboratory (LANL) (2003).

17) P. H. Nelson, J. E. Kibler, A Catalog of Porosity and Permeability from Core Plugs in Siliciclastic Rocks, USGS, Open-file Report, 03-420 (2003).

18) L. Pourcelot, les réacteurs de fission naturels du gabon: contribution à l'étude des conditions de stabilité d'un site naturel de stockage de déchêts radioactifs (2 Ga), thèse doctorat, ULP Strasbourg (1997).

19) D. R. Lide, H. P. R Frederikse Handbook of Chemistry and Physics, CRC editions 1996 (1996).

20) J-P. Tchebina-Makosso, Effets, sur l'encaissant, des reactions de fission naturelles d'Oklo (République Gabonaise) Evolution minéralogique des phyllosilicates et bilans géochimiques, Thèse de Doctorat ( ${ }^{\text {ème }}$ cylce), U.E.R des Sciences de la vie et de la terre, Institut de Géologie Strasbourg (1982).

21) P. Holliger, F. Gauthier-Lafaye, Oklo, analogue naturel de stockage de déchets radioactifs (phase 1), vol. 2, Sciences et Techniques Nucléaires, Final Report (1996).

22) F. Gauthier-Lafaye, Contrôle Géologique de l'exploitation des zones de réaction 7 à 9, Oklo, Gabon, Geology Institute, Louis Pasteur University, Apr.1978 - Sep. (1979).

23) R. Openshaw, M. Pagel, B. Poty "Phases fluids contemporaines de la diagenèse des grès, des mouvements tectoniques et du fonctionnement des réacteurs nucléaires d'Oklo (Gabon)," Proc. Tech. Comm. Meet. On Natural fission reactors, Paris, France, Déc 19-21, 267-290 (1977). 